\title{
Intrathecal Bupivacaine Vs. Bupivacaine And Clonidine In Paediatrics Age Group: A Comparative Evaluation.
}

\author{
$\mathrm{N}$ Jambure
}

\begin{abstract}
Citation
N Jambure. Intrathecal Bupivacaine Vs. Bupivacaine And Clonidine In Paediatrics Age Group: A Comparative Evaluation.. The Internet Journal of Anesthesiology. 2013 Volume 31 Number 1.
\end{abstract}

DOI: $\underline{10.5580 / 2 \mathrm{cc} 9}$

\begin{abstract}
The study was done to compare the efficacy, duration, quality and side effects of intrathecal bupivacaine alone and bupivacaine plus clonidine. A prospective randomised double blind study was carried out in 60 ASA-1 paediatrics patients undergoing surgeries below T8 dermatome up to 2 hrs duration. Patients were randomly allocated in two groups. Group-A received bupivacaine $.5 \%$ heavy $(0.4 \mathrm{mg} / \mathrm{kg}$ for $5-15 \mathrm{~kg}$ or $0.3 \mathrm{mg} / \mathrm{kg}$ for $>15 \mathrm{~kg})$ and Group-B received bupivacaine $0.5 \%$ heavy $(0.4 \mathrm{mg} / \mathrm{kg}$ for $5-15 \mathrm{~kg}$ or $0.3 \mathrm{mg} / \mathrm{kg}$ for $>15 \mathrm{~kg}$ ) and preservative free clonidine (1 mcg/kg), comprising 30 patients each. Time of onset of sensory block, maximum level of sensory block, duration of sensory block, duration of post-op analgesia and side effects were observed. Data obtained was subjected to statistical computation and analysed using computer programme statistical package for social science (SPSS)ver-16.0 and tests performed were unpaired student-t test, nonparametric mann-whitney two samples test and Chi square test. Value of $p<0.05$ was considered significant and $p<0.0000001$ highly significant. Awake sedation score with clonidine was better than bupivacaine alone. The side effect profile: only one patient of Group-A had bradycardia and in Group-B two patients had bradycardia and two patients had hypotension. No patients in any group had nausea vomitting, post dural puncture headache, urinary retention or high spinal. Adding clonidine is providing early onset of sensory block, adequate sedation and prolonged postoperative analgesia.
\end{abstract}

\section{INTRODUCTION}

Pain is a major concern of human kind since our beginning and object of ubiquitous efforts to understand and to control it. Pediatric pain management is challenging and one of the frontiers of modern anesthesia. The first report on paediatric spinal anesthesia was published by AUGUST BIER in 1899, when the technique was performed with cocaine in an 11 year old boy for ischium abscess drainage.

Spinal anaesthesia is advantageous in that it uses small dose of anesthetic, is easy to perform and offers a rapid onset, reliable surgical analgesia and good muscle relaxation.

Advantages sometime offset by relatively short duration of action and complaints of post operative pain when it wears off. Spinal anaesthesia with hyperbaric bupivacaine hydrochloride is popular for longer procedure due to its prolonged duration but there is need to intensify and increased duration of sensory blocked without increasing the intensity and duration of motor blocked and thus prolong the duration of post operative analgesia.

Various studies have shown that $1 \mathrm{mcg} / \mathrm{kg}$ clonidine provides a significant improvement in spinal anaesthesia quality, duration and reduces the need of post-operative analgesic requirement without a significant side effects ${ }^{[1,2,3,4,5,10,11]}$. There is adequate evidence that $\square-2$ adrenergic agonist clonidine given intrathecally produces anti nociceptive effects without any neurotoxicity and useful in the treatment of somatic pain ${ }^{[1,2,3,4]}$. However, unlike spinal opioides clonidine does not produce pruritis and respiratory depression. The rationale behind intrathecal administration of clonidine is to achieve a high drug concentration in the vicinity of - 2 adrenoreceptors in spinal cord by blocking pain conduction of $\mathrm{C}$ and $\mathrm{A}$-delta fibres. It increases potassium conductance in isolated neurons in vitro and intensifies conduction block of local anaesthetic ${ }^{[7]}$. A $\llbracket$ fibres are myelinated afferent sensory nerve fibres which conduct pain, cold temperature and touch sensation, and $\mathrm{C}$ fibres are nonmyelinated postganglionic sympathetic fibres which conduct pain, warm temperature and touch sensation. ${ }^{[8]}$ Clonidine is now an acceptable adjuvant to local anaesthetic for epidural route nevertheless clinical trial provide evidence that less clonidine is needed intrathecaly than epidural to 
produce same analgesic effect with fewer side effects.

In the present study we tried to find out effectiveness of $1 \mathrm{mcg} / \mathrm{kg}$ intrathecal clonidine added to hyperbaric bupivacaine on onset, quality, duration of analgesia and side effects if any in paediatric patients undergoing surgeries below $\mathrm{T} 8$ dermatome.

\section{METHODS}

After approval from local ethical committee of institute and written valid informed consent from parents/guardians of all the patients with grade ASA 1 of physical status weight 5-30 $\mathrm{kg}$ and age 3-10 years and surgeries below T8 were enrolled for the study except those patients with known sensitivity to the drugs, gross spinal deformity and peripheral neuropathy. Patients were randomly allocated into two groups in a double blinded fashion based on computer generated code. Group-A (0.5\% hyperbaric bupivacaine $0.4 \mathrm{mg} / \mathrm{kg}$ for $5-15$ $\mathrm{kg}$ or $0.3 \mathrm{mg} / \mathrm{kg}$ for $>15 \mathrm{~kg})$ and Group-B $(0.5 \%$ hyperbaric bupivacaine $0.4 \mathrm{mg} / \mathrm{kg}$ for $5-15 \mathrm{~kg}$ or $0.3 \mathrm{mg} / \mathrm{kg}$ for $>15$ with $1 \mathrm{mcg} / \mathrm{kg}$ preservative free clonidine). Detailed preoperative evaluation carried out in all patients and vital parameters noted. Routine investigations like complete blood count, BT, CT, random BSL, urine routine microscopy were done. Patients were properly monitored in operation theatre and baseline parameters were noted. Monitoring commenced with pulse-ox meter(spo2), and NIBP. A peripheral venous access with $22 / 24 \mathrm{G}$ cannula was secured on the dorsum of the hand but there was no fluid preloading. They were premedicated with glycopyrolate $4 \mathrm{mcg} / \mathrm{kg}$ iv before lumbar puncture. Patients were induced with $\mathrm{O} 2$ and sevoflurane for 3 minutes. Lumbar puncture was done in the L4/L5 interspaces' with disposable hypodermic needles $(27 \mathrm{G} * 1.5$ inches). Correct needle position confirmed by free CSF flow and the calculated dose of drug i.e. either bupivacaine alone (Group-A) or bupivacaine plus clonidine (Group-B) injected intrathecaly without barbotage. Patients then were immediately placed in supine position with slight head elevation. Intra-operative fluid was given by using 4-2-1 formula. i.e. holiday seggar. After blocked following parameters related to sensory level were noted.

1-time of onset of sensory blocked.

2-maximum level of sensory blocked achieved.

3-duration of sensory blocked.

Onset of block was defined as loss of sensitivity at the same dermatome level as lumbar puncture. The level of sensory block was determined by attempting to elicit grimace or acknowledgement of pain to bilateral pin prick at each dermatome from caudal to cephalad direction every 2 minutes. The adequacy of spinal anaesthesia was determined by the presence of profound motor block at ankles, knees and hip joints. Patients with failed spinal block were excluded from this study and surgery was performed under general anesthesia. Vital parameters like HR, BP. RR, peripheral $\mathrm{O} 2$ saturation, sedation score were noted every min for 5 minutess thereafter every 5 minutes for 30 minutes, then every 30 minutes till 2 hours, then at the $3^{\text {rd }}$ hour and then every 2 hours for 12 hours. Intraoperatively sedation is graded as follows-

0-eye opening spontaneously

1-eye opening to speech

2-eye opening when shaken

3-unarousable

Duration of surgery was noted. At the end of surgery, no prophylactic pain relief was given and patients were transferred to post anesthesia care unit and monitoring was continued for vital parameters, Sedation score and level of sensory blocked was noted every 30 minutes for first 2 hours, every hour for next 12 hours. Duration of sensory blockade was defined as - the time from injection of subarachnoid drug till the level of regression up to L5-S1 and it was assessed by reappearance of sensation on heel and sole of foot.

Postoperative pain was assessed by Modified objective pain score $^{[11,13]}$, given maximum score of 10 . Modified objective pain score is used to assess the pain over a 5 minute period every hour. The higher the score the greater the pain experienced by the patient. When objective pain score was more than 4, end point of observation and rescue analgesic was given.

\section{Figure 1}

\begin{tabular}{|c|c|c|c|}
\hline Variable & Score 0 & Score 1 & Score 2 \\
\hline Crying & None & Consolable & Not consolable \\
\hline Movement & None & Restless & Thrashing \\
\hline Agitation & Asleep/calm & Mild & Hysterical \\
\hline Posture & Normal & Flexed & $\begin{array}{c}\text { Holds injury } \\
\text { site }\end{array}$ \\
\hline VerbaL & $\begin{array}{c}\text { Asleep } / \text { no } \\
\text { complain }\end{array}$ & $\begin{array}{c}\text { Complains but } \\
\text { cannot localize }\end{array}$ & $\begin{array}{c}\text { Complains can } \\
\text { localize }\end{array}$ \\
\hline
\end{tabular}

Duration of analgesia was considered as interval from time 
of intrathecal injection to the time of rescue analgesic demanded postoperatively. The total numbers of analgesic doses needed in the first 12 hours were noted. All the patients were observed for any side effects or complications in the post-operative period for 12 hours and following complications if occurred were noted and treated with conventional methods

Hypotension- fall of blood pressure $>20 \%$ from baseline was considered as hypotension. It was treated with intravenous fluid administration, raising the foot end, oxygen inhalation and vasopressor agents. Physiological impact of sympthectomy is minimal or none in small age groups. ${ }^{[16]}$

Bradycardia- fall of heart rate $>20 \%$ from baseline was considered as bradycardia and was treated with inj. atropine $10 \mathrm{mcg} / \mathrm{kg}$ administered intravenously watching for other vital parameters.

Desaturation- saturation $<90 \%$ was treated with oxygen supplementation.

High spinal level.

Urinary retention.

Excessive Sedation.

Post-Dural puncture headache (PDPH) - for prevention of PDPH - use of smaller gauge spinal needle and good hydration (preoperative and intraoperative) though PDPH is low in pediatric patients. ${ }^{[16,18,19,20]}$

Transient neurological syndrome or other neurological disorder/deficit.

\section{RESULTS}

The present study was conducted in 60 ASA-I paediatric patients undergoing surgeries below T8 dermatome to compare the efficacy, duration, quality of spinal blockade and side effect if any between intrathecal bupivacaine alone and clonidine added to intrathecal bupivacaine. Thirty patients were randomly allocated in each of the following two groups.

\section{Figure 2}

Table-1 Demographic data and duration of surgery:-

\begin{tabular}{|l|c|c|c|c|c|}
\hline & Age (years) & Weight(kg) & $\mathbf{m}$ & $\mathbf{f}$ & $\begin{array}{c}\text { Duration of } \\
\text { surgery }\end{array}$ \\
\hline $\begin{array}{l}\text { Group A (n=30) } \\
\text { (mean } \pm \mathbf{s d )}\end{array}$ & $5.83 \pm 2.7678$ & $19.06 \pm 6.7565$ & 2 & 3 & $46.3 \pm 13.1$ \\
\hline $\begin{array}{l}\text { Group B (n=30) } \\
\text { (mean } \pm \mathbf{s d )}\end{array}$ & $6.2 \pm 2.329$ & $17.56 \pm 6.8101$ & 2 & 3 & $52.83 \pm 16.272$ \\
\hline P value & 0.586 & 0.395 & 1.000 & 0.093 \\
\hline
\end{tabular}

For age and weight $\mathrm{P}>0.05$ non- significant.

Demographic profiles of the patients is comparable with respect to age and weight. Distribution per ASA status are similar in both the group.

\section{Figure 3}

Table-2 Comparison of initial block characteristics.

\begin{tabular}{|l|l|l|l|}
\hline & $\begin{array}{l}\text { Group-A (n=30) } \\
\text { (mean } \pm \text { sd) }\end{array}$ & $\begin{array}{l}\text { Group-B (n=30) } \\
\text { (mean } \pm \text { sd) }\end{array}$ & P value \\
\hline $\begin{array}{l}\text { Onset of } \\
\text { sensory block }\end{array}$ & $4.8 \pm 1.54$ & $3.1667 \pm 1.4162$ & $<0.0000001$ \\
\hline $\begin{array}{l}\text { Duration of } \\
\text { sensory block }\end{array}$ & $110.07 \pm 10.8$ & $168.63 \pm 7.0783$ & $<0.0000001$ \\
\hline $\begin{array}{l}\text { Two segment } \\
\text { regression }\end{array}$ & $82.3 \pm 11.13$ & $112.8 \pm 9.58$ & $<0.0000001$ \\
\hline
\end{tabular}

p-value $<0.0000001$ i.e. highly significant.

Addition of clonidine to bupivacaaine as an adjuvant result in earlier onset of sensory block(3.1667 \pm 1.4162$)$ and more duration of sensory block $(168.63 \pm 7.0783)$ compare to bupivacaine alone, i.e.. ( $4.8 \pm 1.54)$ and (110.07 \pm 10.8$)$ respectively ${ }^{[11]}$. All these initial block characteristics turn out to be statistically significant values on comparison i.e. $\mathrm{p}<0.0000001$.

\section{Figure 4}

Table-3 Comparison of modified objective pain scores between Group A and Group B:

\begin{tabular}{|c|c|c|c|c|}
\hline $\begin{array}{c}\text { Du } \\
\text { ration }\end{array}$ & $\begin{array}{c}\text { Group A } \\
\text { mean } \pm \text { sd }\end{array}$ & $\begin{array}{c}\text { Group B } \\
\text { mean } \pm \text { sd }\end{array}$ & P value & Sign \\
\hline Shift & 0 & 0 & - & NS \\
\hline $30 \mathrm{~min}$ & $0.2333 \pm 0.5683$ & 0 & 0.02836 & Sign \\
\hline $1 \mathrm{hr}$ & $2.266 \pm 1.38$ & $0.333 \pm 0.711$ & $<0.0000001$ & Sign \\
\hline $2 \mathrm{hr}$ & $5.4 \pm 1.1919$ & $1.767 \pm 1.278$ & $<0.0000001$ & Sign \\
\hline $4 \mathrm{hr}$ & $4.3333 \pm 1.02833$ & $3.27 \pm 1.2$ & 0.0004868 & Sign \\
\hline $6 \mathrm{hr}$ & $3.7 \pm 0.7497$ & $2.87 \pm 0.78$ & 0.000084 & Sign \\
\hline $8 \mathrm{hr}$ & $3.266 \pm 0.5833$ & $2.2 \pm 0.71$ & $<0.0000001$ & Sign \\
\hline $10 \mathrm{hr}$ & $2.8333 \pm 0.5921$ & $1.8 \pm 0.48$ & $<0.0000001$ & Sign \\
\hline $12 \mathrm{hr}$ & $2.6666 \pm 0.6144$ & $1.5 \pm 0.51$ & $<0.0000001$ & Sign \\
\hline
\end{tabular}

The changes in objective pain score for pain were noted. 
Comparison was done by applying unpaired t 'test.

Significant difference was found from 30 min after shifting up to 12 hours. Objective pain score were low in Group B as compared to Group A

\section{Figure 5}

Table-4 Comparison of sedation score:-

\begin{tabular}{|c|c|c|c|c|c|c|}
\hline & \multicolumn{2}{|c|}{ Group A } & \multicolumn{2}{c|}{$\begin{array}{c}\text { Group B } \\
\text { Unpaired t }- \\
\text { test }\end{array}$} \\
\hline Time & Mean & SD & Mean & SD & P-Value & Sign. \\
\hline 15 min & 0 & 0 & 0.266 & 0.305 & $<0.005$ & Sign. \\
\hline $20 \mathrm{~min}$ & 0.1 & 0.3051 & 0.7333 & 0.4498 & $<0.005$ & Sign. \\
\hline $25 \mathrm{~min}$ & 0.2 & 0.407 & 0.933 & 0.365 & $<0.005$ & Sign. \\
\hline $30 \mathrm{~min}$ & 0.3 & 0.4661 & 1.13 & 0.346 & $<0.005$ & Sign. \\
\hline $60 \mathrm{~min}$ & 0.3 & 0.466 & 1.2 & 0.4068 & $<0.005$ & Sign. \\
\hline $90 \mathrm{~min}$ & 0 & 0 & 1.06 & 0.254 & $<0.005$ & Sign. \\
\hline $120 \mathrm{~min}$ & 0 & 0 & 0.83 & 0.379 & $<0.005$ & Sign. \\
\hline $3 \mathrm{hrs}$ & 0 & 0 & 0.17 & 0.38 & $<0.005$ & Sign. \\
\hline
\end{tabular}

The above table shows that the sedation score was significant right from 15 minutes to 3 hours after subarachnoid block. It shows Group B patients are more sedated than Group A patients. Clonidine is a popular sedative agent nowadays. Similar findings are observed in our study. Mean sedation scores were higher in Group B than Group $\mathrm{A}^{[10,12,13,14]}$ and significant statistically i.e. $=<0.0000001$

\section{Figure 6}

Table:-5 Post operative block characteristics in minutes:-

\begin{tabular}{|l|c|c|c|}
\hline & Group A & Group B & P value \\
\hline 2 segment regression & $82.3 \pm 11.13$ & $112.8 \pm 9.58$ & $<0.0000001$ \\
\hline $\begin{array}{l}\text { Total duration of post- } \\
\text { operative analgesia }\end{array}$ & $191 \pm 21.551$ & $365 \pm 84.578$ & $<0.0000001$ \\
\hline $\begin{array}{l}\text { Total no of analgesics in } \\
\text { 12 hours }\end{array}$ & $2.4666 \pm 0.5074$ & $1.5 \pm 0.6297$ & $<0.0000001$ \\
\hline
\end{tabular}

Findings of table 5 reveals statistically significant values on comparison of post operative block characteristics among the two groups. Clonidine provided the smooth and prolong postoperative analgesia as compared to bupivacaine alone ${ }^{[9,11]}$. The evidence was very much visible in the prolong time to two segmental dermatomal regression ${ }^{[11,13]}$ in Group B.i.e. 112.8 \pm 9.58 . As a result time of rescue analgesia ${ }^{[9,11,13]}$ was comparatively shorter $191 \pm 21.551$ in Group A than Group B. $\mathrm{p}<0.0000001$.

\section{Figure 7}

Table-6 Comparison of Adverse Effects in Both Groups:

\begin{tabular}{|c|c|c|}
\hline Side Effects & Group A & Group B \\
\hline Bradycardia & 1 & 2 \\
\hline Hypotension & 0 & 2 \\
\hline Nausea/ Vomiting & 0 & 0 \\
\hline High spinal & 0 & 0 \\
\hline PDPH & 0 & 0 \\
\hline Urinary Retention & 0 & 0 \\
\hline
\end{tabular}

Table 6 shows the incidence of side effects in all groups. Bradycardia was found in 1 cases of group A and 2 cases of Group B. Hypotension was observed in 0 cases of group A and 2 cases of group B. No patient in any group had nausea/vomiting, PDPH, urinary retention or high spinal level.

\section{DISCUSSION}

The subarachnoid block is a popular, simple and reliable anaesthetic technique for lower abdominal and lower limb surgeries. It has been used widely in clinical practice of anaesthesia because of rapid onset, high reliability and low cost. It produces excellent operating conditions and has high success rate. Though it provides effective analgesia in the initial postoperative period, the effect needs supplementation of potent opioid analgesics systemically to extend the period. Systemic opioids have been associated with respiratory depression, nausea, and vomiting, itching, and urinary retention. Subarachnoid block last shorter in children than adults because of rapid pharmacokinetics in children as compared to adult. Hence, attempts were made to increase duration of analgesia produced by subarachnoid block by adding various agents intrathecally, like opioids e.g. morphine, buprenorphine, hydromorphone, fentanyl, and non-opioids e.g. ketamine, neostigmine, but none of them have been accepted in clinical practice due to their side effect or non-availability

Spinal anaesthesia is an excellent option in paediatric population as it provides a rapid onset of profound and predictable uniformly distributed analgesia with good neuromuscular blockade. Paediatric spinal anaesthesia has proven to be a safe alternative to routinely administered general anaesthesia as it avoids the polypharmacy associated with the latter technique and also reduces the incidence of post-operative respiratory complications associated with administration of general anaesthesia ${ }^{[15]}$. In our study, we evaluate and compare the effects of intrathecal clonidine 1 $\mu \mathrm{g} / \mathrm{kg}$ added to hyperbaric bupivacaine $0.5 \%$ and intrathecal bupivacaine alone on the quality of subarachnoid block, 
postoperative analgesia and side effects in patients undergoing lower abdominal surgeries. The demographic profile of our patients comparable with respect to age,weight,sex,ASA grading and duration of surgery.Results of study shows that addition of clonidine $1 \mathrm{mcg} / \mathrm{kg}$ to bupivacaine $0.5 \%$ hastens the onset of analgesia, increases the time to regression of sensory block, longer duration of sensory block and decreased need of analgesic. Clonidine has a visible edge over bupivacaine alone as it enables earlier onset and established a sensory time of block.

The results of our study clearly indicate the effectiveness of intrathecal clonidine as a profound sedative $\mathrm{e}^{[10,12,13]}$ and the patients were arousable by gentle tactile stimulation. Overall sedation scores was highly significant statistically with administration of clonidine. In all patients spo 2 maintained more than $90 \%$.

The group-A shown visible superiority over various post operative block characteristics like regression of sensory block, prolonged post-operative analgesia, lesser amount of analgesic requirement post- operatively. Cardiorespiratory parameters as evident from figure-1

\section{Figure 8}

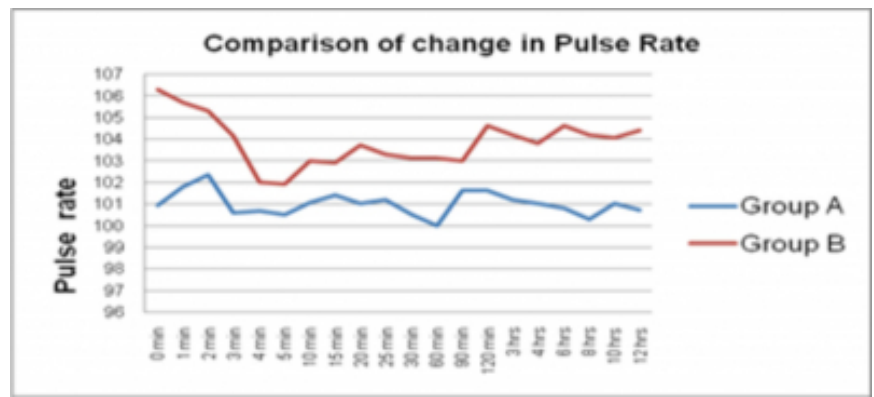

Statistically significant difference was not found in two groups in terms of pulse rate throughout the observation period.

\section{Figure 9}



Systolic blood pressure in both the groups fell after induction and return back to near preoperative level.
Difference of fall in blood pressures between the groups at different time intervals studied was statistically not significant. No patient in any group had nausea, PDPH, vomiting, urinary retention and high spinal level although one case of bradycardia was found in group-A and two cases of bradycardia and two cases of hypotension were found in group-B.These side effects were not significant on statistical comparison.

\section{CONCLUSIONS}

We conclude that clonidine is better adjuvant to bupivacaine in spinal anaesthesia as far as patients comfort is concerned. It decreases the time taken for onset, produces longer duration of both surgical anaesthesia and post operative analgesia and better quality of sedation with no added side effects as compare to bupivacaine alone, in paediatric patients undergoing surgeries below T8 dermatome.

\section{References}

1. Chiari A, EisenachJC. Spinal anesthesia: mechanisms, agents, methods, and safety. Reg Anesth Pain Med 1998; 23(4):357-62.

2. Racle JP, Benkhadra A, Poy JY, Gleizal B. Prolongation of isobaric bupivacaine spinal anesthesia with epinephrine and clonidine for hip surgery in the elderly. Anesth Analg 1987; 66 (5):442-46.

3. Dobrydnjov I, Samarutel J. Enhancement of intrathecal lidocaine by addition of local and systemic clonidine. Acta Anaesthesiol Scand 1999; 43(5):556-62.

4. Bonnet F, Buisson VB, Francois Y, Catoire P, Saada M. Effects of oral and subarachnoid clonidine on spinal anesthesia with bupivacaine. Reg Anesth 1990; 15(4): 211-14.

5. Niemi L. Effects of intrathecal clonidine on duration of bupivacaine spinal anaesthesia, haemodynamics, and postoperative analgesia in patients undergoing knee arthroscopy. Acta Anaesthesiol Scand 1994; 38(7):724-8.

6. Dobrydnjov I, Axelsson K, Samarutel J, Holmstrom B. Postoperative pain relief following intrathecal bupivacaine combined with intrathecal or oral clonidine. Acta Anaesthesiol Scand 2002; 46(7):806-14.

7. Sethi BS, Samuel M, Sreevastava D. Efficacy of Analgesic Effects of Low Dose Intrathecal Clonidine as Adjuvant to Bupivacaine. Indian Journal of Anaesthesia 2007; 51(5): 415-19.

8. Strichartz G, Berde C. Local Anesthetics. In, Miller RD (ed). Miller's Anesthesia, 6th edition. New York: Churchill Livingstone Inc, 2005:573-603.

9. Kaabachi O, Ben Rajeb A, Mebazaa M, Safi H, Jelel C, Ben Ghachem M, Ben Ammar M. Spinal anesthesia in children: comparative study of hyperbaric bupivacaine with or without clonidine. Ann Fr Anesth Reanim. 2002; 21(8):617-21.

10. Rochette A, Raux O, Troncin R, Dadure C, Capdevila X.Clonidine prolongs spinal anesthesia in newborns: a prospective dose-ranging study. Anesth Analg 2004; 98(1):56-9.

11. Kaabachi O, Zaraghouni A, Ouezini R, Abdelaziz AB, Chattaouni O, Kokki H. Clonidine $1 \square \mathrm{g} / \mathrm{kg}$ is a safe and effective adjuvant to plain bupivacaine in spinal anesthesa in 
adolescents. Anesth Analg 2007; 105(2):516-9.

12. Batra YK, Rakesh SV, Panda NB, Lokesh VC,

Subramanyam R.Intrathecal clonidine decreases propofol sedation requirements during spinal anesthesia in infants. Paediatr Anaesth 2010; 20(7):625-32.

13. Cao JP, Miao XY, Liu J, Shi XY.An evaluation of intrathecal bupivacaine combined with intrathecal or intravenous clonidine in children undergoing orthopedic surgery: a randomized double-blinded study. Paediatr Anaesth. 2011; 21(4):399-405.

14. De Sarro GB, Ascioti C, Froio F, Libri V, Nisticò G.

Evidence that locus coeruleus is the site where clonidine and drugs acting at alpha 1-and alpha 2-adrenoceptors affect sleep and arousal mechanisms. Br J Pharmacol 1987; 90(4):675-85.

15. Kokki H, Hendolin H, Vainio J, Partanen J. Comparison of Spinal Anaesthesia and General Anaesthesia; Anaesthetist 1992; 41(12):765-8.

16. Goyal R, Ginjil K, Baj BB, Singh S, Kumar S. Paediatric spinal anaesthesia..Indian J Anaesth 2008; 52 (3): 264-70. 17. Imbelloni LE, Vieira EM, Beato L, Sperni F. Spinal anesthesia for outpatient pediatric surgery in $1-5$ years old children with $0.5 \%$ isobaric enantiomeric mixture of bupivacaine (S75-R25). Rev Bras Anestesiol 2002; 52(3):286-93.

18. Imbelloni LE, Vieira EM, Sperni F, Guizellini RH, Tolentino P. Spinal anesthesia in children with isobaric local anesthetics:report on 307 patients under 13 years of age. Paediatr Anaesth 2006; 16(1):43-8.

19. Kokki H, Hendolin H, Turunen M. Postdural puncture headache and transient neurologic symptoms in children after spinal anaesthesia using cutting and pencil point paediatric spinal needles. Acta Anaesthesiol Scand 1998; 42: 1076-82.

20. Puncuh F, Lampugnani E, Kokki H. Use of spinal anaesthesia in paediatric patients: a single centre experience with 1132 cases. Pediatric Anesthesia 2004; 14: 564-67. 


\section{Author Information}

Nagesh Jambure

MGM Medical College

Maharashtra, India

drnagesh83@gmail.com 